\title{
Configurações
}

Revista de sociologia

\section{A plasticidade dos usos do crioulo em contexto prisional}

Daily details of young foreign inmates in Portugal: a case study

Détails quotidiens de jeunes étrangers emprisonnés au Portugal : une étude de cas

\section{Cláudia Resende}

\section{CpenEdition}

\section{Journals}

Edição electrónica

URL: http://journals.openedition.org/configuracoes/4212

DOI: 10.4000/configuracoes.4212

ISSN: 2182-7419

\section{Editora}

Centro de Investigação em Ciências Sociais

\section{Edição impressa}

Paginação: 75-92

ISSN: 1646-5075

\section{Refêrencia eletrónica}

Cláudia Resende, "A plasticidade dos usos do crioulo em contexto prisional », Configurações [Online], 20 | 2017, posto online no dia 28 dezembro 2017, consultado o 23 abril 2019. URL : http:// journals.openedition.org/configuracoes/4212 ; DOI : 10.4000/configuracoes.4212 
Resende, Cláudia - A plasticidade dos usos do crioulo em contexto prisional. Configurações, vol. 20, 2017, pp. 75-92.

\title{
A plasticidade dos usos do crioulo em contexto prisional
}

\author{
CLÁUDIA RESENDE* \\ Direção Geral de Reinserção Social e Serviços Prisionais
}

\begin{abstract}
Resumo
Este texto analisará encontros informais de cidadãos com pertença nacional de CaboVerde e da Guiné-Bissau com especial destaque para a polivalência do uso das suas línguas maternas uma vez em cumprimento de uma pena efetiva de prisão. Esta investigação aplicou técnicas intensivas através de uma abordagem etnográfica às alas de um estabelecimento prisional masculino insular português de regime fechado, a qual contou com a partilha espontânea e consentida de objetos quotidianos dos participantes da amostra. A partir de notas de campo / observações empíricas / material voluntariamente facultado, foram feitas entrevistas em profundidade. A título supletivo, foram tiradas fotografias mediante anuência de todas as partes e com salvaguarda de resguardo. É evidenciado como a utilização falada do crioulo entre pares de reclusão pode ser metamorfoseada enquanto parte intrínseca da formulação de práticas de lazer e enquanto elemento inerente de estratégias de "sobrevivência institucional" no sentido de compensação de pressões e lacunas derivadas da restrição de liberdade.
\end{abstract}

Palavras-chave: Estrangeiros, Crioulo, Lazer, Prisão .
Abstract
Daily details of young foreign inmates in Portugal: a case study
This paper will address daily dynamics upon leisure as promoted by young foreign male inmates who were under a custodial sentence within a Portuguese prison facility.
Under the scope of the Portuguese academic field, the extent to which this research is original will be explained, as far as the study of foreign inmates is concerned.
The participants of the sample have demonstrated ability to recreate moments in which traces of their symbolic heritage and sociocultural belongings were reconstituted with contours of the prison environment.

\footnotetext{
* Socióloga / Investigadora independente. E-mail: macutailunga@gmail.com; claudia.f.resende@dgrsp.
} mj.pt 
A particular aspect - the linguist one - will be underlined, namely through the expression of their mother tongue, such as the creole.

Keywords: Foreigners, Youth, Confinement, Collective imagery, Creole.

\section{Résumé}

«Détails quotidiens de jeunes étrangers emprisonnés au Portugal : une étude de cas» Cette communication présentera les dynamiques quotidiennes centrées sur les loisirs, telles qu'elles sont vécues par des jeunes hommes de nationalité autre que portugaise purgeant une peine de prison ferme dans un établissement pénitentiaire au Portugal. Suivant le panorama académique portugais, l'accent sera mis sur l'originalité de cette recherche empirique, concernant l'étude des étrangers en milieu carcéral.

Les jeunes de l'échantillon ont montré une capacité à recréer des moments où ils reconstituent leur patrimoine culturel d'origine, au travers de points de repère antérieurs à l'incarcération.

Il faut souligner un trait socioculturel en particulier, qui est celui du partage linguistique, notamment par l'utilisation du créole.

Mots-clés: Étrangers, Jeunes, Réclusion, Imaginaire collectif, Créole.

\section{Introdução}

Este artigo dá enfoque a detalhes quotidianos ocorridos em ambiente prisional por parte de estrangeiros sob condenação efetiva com cidadania oficial de Guiné Bissau e de Cabo-Verde. Procurara-se dar a perceber que propósitos e particularidades podem estar contidos nos usos do crioulo de Cabo-Verde (Ilha de Santiago) e do crioulo da Guiné Bissau enquanto elemento indissociável do lazer e enquanto estratégia de "sobrevivência institucional".

Numa primeira parte, são contextualizadas a incidência e a prevalência de cidadãos estrangeiros no parque penitenciário europeu, com as principais preocupações académicas que têm vindo a ser suscitadas sobre essa expansividade numérica; numa segunda parte, são sublinhadas algumas linhas tendenciais do sistema judicial português face aos não-nacionais que se encontram sob sua alçada a par de algumas considerações sociográficas sobre o mosaico de nacionalidades patente no seu sistema prisional; numa terceira parte, são explicitadas as questões-chave que moveram a intenção empírica deste estudo de caso; numa quarta parte, são apresentados o enquadramento teórico, os conceitos germinais e a bateria metodológica desta investigação; numa quinta parte, os episódios quotidianos são expostos e interpretados segundo "relatos na primeira pessoa” ["first-person narratives" (Kaufman e Bosworth, 2013: 16)], com especial tónica nos intentos e nas nuances dos usos da língua materna de falantes de crioulo de cidadãos de nacionalidade cabo-verdiana e guineense num meio institucional com características sui generis como seja o prisional; numa sexta parte, é elaborada uma síntese conclusiva.

\section{Sistema criminal de justiça Europeu: um breve panorama}

A prisão apresenta-se como a ponta do iceberg de uma política de prevenção criminal enviesada. Nessa medida, a instância prisional tem vindo a explicitar-se enquanto um regulador social através do controlo criminal ao aglutinar bolsas de exclusão social (Wacquant, 2004). No panorama euro-americano, quer a montante quer a jusante, a vertente penal tem-se assumido enquanto um barómetro de fluxos imigratórios (Mulgrew, 2016; Hasselberg, 2014; Ugelvik, 2014; Garland, 2001).

Em traços gerais, a tendência para uma maior austeridade penal face à presença de não nacionais no território europeu ocidental tem suscitado uma maior incidência e prevalência por parte de cidadãos estrangeiros no parque penitenciário europeu (SPACE I, [2017 (2015)]; Mulgrew, 2016; Ugelvik, 2014, 2014 a; Kalmouth, Der Meulen e Dunkel, 2007; Kaufman e Bosworth, 2013; Wacquant, 1999). Esse crescimento progressivo, mesmo que oscilante, tem movido académicos a tentar perceber até que ponto as intervenções penitenciárias têm conseguido estar na letra do dia face às necessidades e especificidades desta diversidade de referenciais identitários no âmago do seio prisional. Em traços largos, as respostas reabilitativas têm-se revelado anémicas, avulsas ou mesmo arbitrárias, conforme o que tem vindo a ser identificado quer pelos estrangeiros em reclusão (Gomes, 2017; Turnbull e Hasselberg, 2016; Trombik, 2007; Moraes Rocha, 2001); quer pelos staffs prisionais (RuizGarcia e Castillo-Algarra, 2014; Gomes, Machado e Silva, 2012; Hostettler e Acherman, 2008; Kalmouth et al., 2007). Com efeito, temos um maior número de estudos qualitativos no panorama prisional europeu por forma a perceber quer a eficiência quer a lassidão dos staffs prisionais em fazer face a várias questões sensíveis relativas a cidadãos não nacionais sob tutela penitenciária (Mulgrew, 2016 a; Slade, 2016) bem como as vivências prisionais de convivência social (Martynowicz, 2016; Shammas, 2015; Ugelvik, 2014 a; Cunha, 2002).

Atualmente, o caso inglês tem sido seguido sob a ótica criminológica com particular atenção dado que a concentração de estrangeiros em prisões exclusivas com vista a uma suposta melhor intervenção reabilitativa tem feito perigar o próprio conceito de "reabilitação" (Kanton e Hammond, 2012; Turnbull e Hasselberg, 2016, Hasselberg, 2014). Os cidadãos não nacionais sob tutela penitenciária ficam mais facilmente identificáveis pelas forças de controlo de fronteiras, o que agiliza e garante o processo de expulsão no pós-reclusão, o que tende a corporalizar-se em experiências prisionais assentes em momentos de angústia, frustração e ambivalência (Hasselberg, 2014). Todavia, é também da experiência prisional inglesa que encontramos outros investigadores que 
elencam as possibilidades de proatividade institucional face aos estrangeiros em lato senso ou com subpertenças específicas (Shing Bhui, 2004; YOUNG REVIEW TASK GROUP, 2014).

\section{Panorama prisional português}

Em Portugal, em termos proporcionais, a fatia percentual de estrangeiros no universo prisional tem um peso estatístico relativo bastante menor que a dos nacionais, com algumas variações pouco acentuadas no curso do passado recente $[16,00 \%$ entre 1 e 15 de setembro de 2017; 15, 9\% entre 1 e 15 de junho de 2017; 16, $60 \%$ entre 1 e 15 de fevereiro de 2017, conforme em DGRSP - intranet]. Porém, essa expressividade é apontada como acentuada (Matos et al., 2013; Esteves e Malheiros, 1999) tendo em conta a presença global de estrangeiros no extramuros. Se atentarmos para um recorte estatístico do $2^{\circ}$ semestre de 2011 (DGSP, 2011) tínhamos um maior equilíbrio proporcional do que temos volvidos seis anos $[20.4 \%$ em contraste à presente estabilidade próxima aos $16 \%$ ] (1 a 15 de setembro de 2017, DGRSP [intranet]).

A fotografia penitenciária portuguesa não tem os mesmos rasgos do que o caso belga em que a expressão numérica dos estrangeiros em privação de liberdade tem sido considerada sintomática e alarmante no sentido de estar a consolidar-se uma tendência para uma maior proporção de não nacionais que nacionais no seio desse sistema prisional (Brion, 2013). Por outras palavras, no caso português, o busílis não se afigura tanto em sublinhar uma presença desmedida de não-nacionais face aos nacionais aquando na filigrana do contexto prisional, mas questionar se esses estrangeiros podem exercer todos os direitos que lhes são, em teoria, indeclináveis. Ou seja, se podem viver a sua cidadania em iguais condições de circunstância do que os seus pares de reclusão nacionais (Matos, 2016; Turnbull e Hasselberg, 2016; Paulino, Conduto e Pires, 2014).

\section{Questões de partida}

Nas malhas da reclusão, o estrangeiro pode estar mais suscetível a se considerar e de ser considerado enquanto o estranho face à maior possibilidade de falta de empatia por parte de terceiros a muitos aspetos que são estimáveis para si. Em contraste, o tempo em reclusão pode ser aproveitado para fazer aproximações e distanciamentos socioculturais (no plano mental e / ou nas práticas sociais) relativamente: a quem se encontre em idêntica condição de reclusão; à sociedade envolvente imediata (Ugelvik, 2014 a); à sua sociedade de origem e / ou outros referenciais estimulados pelos processos de globalização. $\mathrm{O}$ ambiente prisional poderá ser vivenciado com matizes diversas mediante os sentidos de pertença e de referência de cada grupo nacional, sendo que mesmo dentro deste, podemos encontrar dissimilitudes.

Suscitava-se um questionamento de partida:
Em que medida é que os estrangeiros em reclusão lidariam com uma pena efetiva de prisão?

Até que ponto é que os estrangeiros recluídos (re)criariam práticas de lazer, enquanto fórmulas transformativas de distensão e diversão, por compensação aos constrangimentos imanentes?

Será que a prisão anularia, matizava ou salientava a importação de aspetos do património simbólico referencial dos não-nacionais em reclusão?

\section{Enquadramento teórico-empírico}

A moldura teórica escolhida foi a do Interacionismo Simbólico, no sentido que poderia iluminar a importância das significações que os participantes poderiam vir a dar nas e sobre as atividades sociais das quais fazem parte (Blumer, 1992(1969)). Esta corrente teórica apela à não passividade dos sujeitos sociais fazendo por se implicar na redefinição face do contexto envolvente. A observância de um ser social enquanto produtor de reflexividades verbais e práticas, afigurava-se enquanto pertinente para esta investigação, dado que o facto de se estar na condição administrativa de "estrangeiro" sob privação de liberdade não teria que predizer que ora tivesse uma postura de apatia ou ser alvo de compassividade (Resende, 2016).

Nesta investigação, o meio prisional foi apreendido através da natureza episódica e situacional da vida quotidiana (Javeau, 2003). Como tal, revisitou-se um conceito descrito por Goffman (1988), como seja o das interações presenciais focalizadas “(...) enquanto encontros circunstanciados em que duas ou mais pessoas estão em imediata presença umas das outras, concentradas e interessadas entre si, a partir de dado móbil aglutinador de ação, isto é, envolvidos numa atividade mútua” (pp. 193-194).

Os momentos quotidianos dos que se encontram em reclusão poderiam ser imbuídos quer de tensão crispada (Welser-Lang, Mathieu e Faure, 1996) quer de procura de homeostasia e improvisação. Tal como no meio livre (Pais, 2007), a linearidade quotidiana poderia ser pouco linear. Os constrangimentos fixistas tal como as inconstâncias das dinâmicas intraprisionais, podem ser a força motriz de momentos de recriação por parte daqueles que se encontram em subordinação formal penitenciária. No fundo, o crescendo de tensão pode promover a procura de momentos de escape e de relaxamento (Elias e Dunning, 1999(1985)]. Tal como anunciado por Pais (1994), o "lazer" pode emergir, assim, enquanto um ato de rutura, insurreição e criatividade na aparente rigidez dos hábitos do dia-a-dia. O inesperado pode acontecer no torpor da rotina até como forma de contornar o alinhamento previsível do que se espera ver repetido. Nessa ótica, esta investigação visava saber se o lazer em meio prisional poderia ser um propulsor de práticas de experimentação de sociabilidade 
moldadas pela expressão falada do crioulo. Numa instância formal como seja a prisão, o lazer pode ser materializado com iniciativas de contraste e de resistência inspiradas em especificidades originais reconhecíveis para os envolvidos. Certas atividades sociais com vista ao usufruto do bem-estar podem configurar-se enquanto atos de atenuação ao peso do impacto das consequências associadas ao cumprimento de uma prisão efetiva bem enquanto modalidades de saber lidar com um ambiente social que pode ser pressentido como adverso, quer no plano formal quer no plano informal. Desse modo, o lazer pode ser um denominador comum de atos de "sobrevivência institucional" na medida em que esses momentos podem conseguir compensar pungências do ambiente social envolvente. Sendo que o seio prisional pode ser eminentemente conflitual, a equação entre as interpretações que cada um faz sobre o contexto imediato e sobre as intenções terceiras, resulta em respostas práticas de sentido de coligação ou de antagonismo aberto. (Edgar, O’Donnel, Martin, 2012)

Nessa ótica, visou-se a focagem situacional em detrimento da extensidade. Preferiu-se o zoom empírico dos detalhes sociais em prol da extrapolação, com o intento de descortinar dinâmicas informais tal como observadas in situ de maneira a constatar se as pertenças-chave socioculturais dos participantes da amostra seriam dispostas por contrabalanço a um ambiente institucional relativamente homogeneizador e unionista.

Nessa perspetiva, considerou-se um conceito introduzido por Bandyopadhyay (2010), autora essa inspirada no legado do Interacionismo Simbólico, que era ao mesmo tempo uma ótica teórica e um instrumento metodológico: A prisão entendida enquanto "espaço interaccional" (Bandyopadhyay, 2010: pp: 27) (Tradução livre).

Para a pesquisa descrita neste texto, partiu-se da classificação oficial de "estrangeiro", isto é, aquele que não fosse portador de documento oficial português. Em Portugal, não existem estabelecimentos prisionais exclusivos para estrangeiros, pelo que se pode encontrar uma panóplia de nacionalidades por Estabelecimento Prisional, com forte predomínio de nacionais do Brasil, CaboVerde, Guiné-Bissau e Roménia, o que mais uma vez coincide com o entrecruzamento entre trajetórias de vida feitas quer nas linhas de imigração quer dos crimes transatlânticos (Boe, 2016; Oliveira e Gomes, N., 2014; Matos, Barbosa, Salgueira e Machado, 2013; Ferreira Mendes, 2010). Embora na população reclusa geral haja um grande predomínio de nacionais portugueses, dentro da população reclusa estrangeira, existe sobretudo nos centros urbanos um grande mosaico com as mais variadas nacionalidades havendo caracteristicamente uma grande internacionalização reclusa.

Escolheu-se um Estabelecimento Prisional que servisse de laboratório social onde se encontrasse uma expressiva heterogeneidade de nacionalidades face ao número absoluto de reclusos alocados a essa unidade operativa (vulgo E. P.). Nesse sentido, optou-se por se ficar atido a um dos Estabelecimentos Prisionais com maior presença de "estrangeiros" por ratio de número total: vinte e seis nacionalidades por setenta e seis estrangeiros afetos a esse Estabelecimento Prisional (DGSP, 2010). Sendo um Estabelecimento de grau de complexidade de gestão elevado, não é um Estabelecimento Prisional de salvaguarda de segurança particularmente distinto (DGRSP [intranet], 2016). A pesquisa in loco foi feita em Alas de um Regime Fechado de um Estabelecimento Prisional insular, bem como desenvolvida em distintos momentos do dia e da semana. O setting empírico onde decorreu a incursão etnográfica era dividido por Alas, inacessíveis entre si, em termos de gestão prisional, sendo que a pesquisa seguiu o princípio da observância da excecionalidade nos momentos do banal quotidiano, a representatividade de nacionalidades por Alas e uma baliza etária que compreendesse aqueles que estivessem na "entrada tardia da idade adulta" (Pais, Bendit e Ferreira, 2011) e que menos facilmente pudessem ter conhecido um ambiente social tão disciplinador antes da atual reclusão (Coyle, 2005), ou seja, jovens adultos. A amostra final ficou composta por nacionais da GuinéBissau, Marrocos, Brasil, Bulgária, Bolívia, Nigéria, Cabo-Verde e Espanha. Os staffs prisionais não estavam previstos no âmbito do estudo, tendo a sua importância aquando no terreno enquanto facilitadores ou obstrutores da iniciativa empírica.

A fase empírica contou com vários momentos como os seguintes: a) Interconhecimento das Alas e espaços laborais, acompanhada de profissionais destacados para o efeito, numa observação distanciada, com registos etnográficos em notas de campo; b) Observação não participante em diversos momentos do dia-a-dia, com ida a diversos espaços internos, incluindo celas e camaratas; c) Circunscrição a episódios de natureza regular ou excecional, com acompanhamento mais incisivo às interações presenciais focalizadas no lazer; $\mathrm{d}$ ) Seleção dos participantes da amostra a partir desses entrecruzamentos; e) Solicitação de objetos de utilização privada ou coletiva designadas autoscopias (Bouvier, 2000) no sentido de ir ao encontro das escolhas, preferências e opções constantes no intimismo quotidiano feito a solo ou em termos socio-grupais; f) Entrevistas em profundidade, feitas com recurso a gravador digital, baseadas nos episódios quotidianos e do material coletado. As entrevistas em profundidade visavam apreender as suas vivências quotidianas em meio prisional, mas estavam abertas a todos os flashbacks e projeções que fluíssem no desenrolar desta técnica intensiva.

Em termos do universo total da amostra, procurou entender-se como é os participantes (re)posicionavam-se face ao meio prisional onde se encontravam, que leituras críticas explicitavam e que estratégias práticas desenvolviam com o intuito de enfrentar a pena de prisão. Essa argumentação narrativa poderia assumir a ordem do simbólico, quer através de locuções verbais quer não-verbais.. Resende (2016) explicitou que os participantes do universo total da amostra demonstraram conseguir desafogar parte do tempo em contexto prisional 
com o recurso a objetos (fotografias, recortes de revistas; livros; cassetes; cds) e recriação original de momentos mais compagináveis com o seu património sociocultural referencial mesmo que tal não fosse feito de forma cristalizada e exclusiva. Para a elaboração deste artigo, escolheu-se fazer o zoom empírico e a meta-análise de dois "relatos na primeira pessoa" ["first-person narratives" (Kaufman e Bosworth, 2013)], no caso, de um nacional guineense e de um nacional cabo-verdiano.

\section{Usos do crioulo nos encontros informais intramuros}

Selecionou-se um traço sociocultural específico valorizado em vivências muito concretas como sejam as relativas à partilha linguística. Realçar-se-á a utilização do crioulo (ciente das suas múltiplas variantes), língua nacional (i. e. língua não oficial) quer de Cabo-Verde, quer da Guiné-Bissau, com o fim de elucidar o quanto este recurso linguístico pode ajudar no carácter transformativo de algumas configurações em torno do lazer no dia-a-dia dos seus falantes no âmago prisional. Além disso, observar-se-ão pontos de contiguidade e dissemelhança nos episódios quotidianos que irão ser circunscritos.

Sobre a escolha destes dois países lusófonos do continente africano, é certo que têm vindo a corresponder com estabilidade temporal (DGRSP / DGSP, 2015; Oliveira e Gomes, N., 2014; DGSP, 2011; Seabra e Santos, 2006) a duas das maiores expressividades numéricas de cidadãos estrangeiros de sexo masculino no parque penitenciário português. Contudo, este estudo de caso dentro do estudo de caso, não se pretende verificável em todos os portadores destas nacionalidades especificadas ao largo de todo o sistema prisional. Os dados empíricos reunidos no presente texto valem pelo seu carácter ilustrativo e de excecionalidade.

$\mathrm{Na}$ cozinha, encontravam-se inúmeros estrangeiros de diferentes nacionalidades a fazer tarefas com vista à realização das refeições do coletivo prisional. Num mosaico de interações presenciais supostamente focadas em tarefas monótonas, era uma constância encontrar o sentido de humor e a interpelação entre pares de reclusão.

A Pais (1998) foi revisitar-se o substrato de que não deve ser feita uma dicotomia entre "trabalho" e "lazer", visto que: "Nos locais de trabalho, por exemplo, os tempos rígidos e obrigacionais coexistem com lazeres de resistência" (sic). Neste posto oficinal, encontrava-se um grupo de nacionais guineenses e um da Gâmbia, os quais estavam como que em forma de pentágono a cortar batatas. Numa das tardes em que se assistia à tarefa repetitiva do corte de batatas, deu para denotar que um deles, mesmo que mais jovem (doravante de nome fictício Holifu), de nacionalidade guineense, tinha uma ascendência muito grande sobre o grupo dentro daquela unidade laboral e fora dele. À falta de ida de um Imã a título regular àquele Estabelecimento Prisional, era ele que fazia de Imã numa mesquita improvisada feita numa sala vazia. Esse líder religioso informal começou a verbalizar frases que os demais repetiam e cantavam enquanto cortavam batatas.

O que era extraordinário para quem assistia de forma surpreendida, foi banalizado pelo próprio em sede de entrevista em profundidade: eram trechos do Alcorão, imaginados entre o corte de uma batata e o descascar de outra, ritmo ritualizado e improvisado, o qual os membros já tinham integrado num formato que, para eles, já era rotineiro. No fluir desses encontros, as práticas linguísticas convocavam uma confissão religiosa comum.

Nesse sentido, o recurso de frases em árabe eram proclamadas e repetidas, intercaladas com o crioulo da Guiné Bissau, sendo esse ritmo linguístico feito em formato de uma fusão. Sendo a religião e a língua, duas componentes essenciais para se (re)conhecer a diversidade identitária guineense (Machado, 1998), Holifu adiantou em momento de entrevista de que conseguia "ler" o Alcorão enquanto estava a fazer várias tarefas laborais, quer sozinho, quer acompanhado e que isso dava uma aceitação interna ao seu próprio devir: "(...) 'tava a fritar, 'tava sozinho, não tenho com quem falar, para me divertir... para passar o tempo rápido, tenho muitas páginas do Alcorão decoradas na cabeça e então vou lendo isto... vou lendo isto porque já sei o significado daquilo, então me faz esquecer muitas coisas... tipo que um gajo está preso..." "Hã, hã... Ele [Alá] é a pessoa que te meteu nessa cadeia, porque é o seu destino... Ele é que vai te tirar daqui, qualquer dia..." Holifu demonstrou uma abnegação perante a sua vida mundana visto que o controlo da sua vida independe de si próprio.

A capacidade de imaginação de conseguir transformar uma atividade laboral num ato religioso complementar ao culto coletivo que fazia na mesquita improvisada e às orações na cela, não foi sobrevalorizada por Holifu no curso da entrevista. Para este participante, a respeitabilidade da sacralidade parecia não depender do contexto físico em que decorre pelo que tratava-se de uma leitura do Alcorão como outra qualquer: "aquela é uma leitura de Alcorão"... (sic).

Além da sua componente religiosa e de evasão mental, Holifu fez associar este tipo de encontros ao gáudio coletivo e coesão grupal com pessoas com alguns referenciais comuns: "maioritariamente, nos estrangeiros que 'tão ali: guineenses, marroquinos, Gâmbia que 'tá ali, são muçulmanos, gosta de ouvir aquilo..." Holifu recontou a importância das horas passadas dentro do espaço laboral para partilharem circunstâncias do passado e do presente, por meio de um "imaginário coletivo", num tempo socialmente diluído (Pais, 1998) e construído (Cunha, 2005). A prisão permite que o ímpeto de passar o tempo / recriar a passagem no tempo fomente interesse e curiosidade sobre um passado longínquo e sobre o qual se aproveita para fortalecer e fazer retrospetiva a referenciais nacionais / da sociedade de origem: "Maioritariamente, fala quando 
um gajo era um puto... Tipo Joshuá, a gente fala de histórias do tempo colonial, eu era puto, não me lembrava bem destas coisas..."

Do mesmo modo que verbaliza lhe faltarem referencias nacionais estruturais, como "os seus Governos" (sic), dos quais sabia pouco à conta do seu percurso imigratório: Guiné-Egipto-Guiné-Bissau-Portugal. Quando com outros nacionais guineenses ou muçulmanos, perguntam-se uns aos outros sobre as suas vivências dentro das Alas, como se houvesse um sentido protetor gregário. É de esclarecer que o culto muçulmano improvisado era das poucas exceções que permitia o acesso de praticantes muçulmanos de várias Alas, o que permite quer a unicidade linguística (crioulo enquanto língua materna) quer o bilinguismo (a título de exemplo, crioulo e árabe). Sobre as experiências de racismo dentro do amago prisional, foi o próprio que disse: "Na minha Ala é tranquilo, eu sou o único preto... porque ali não faz diferença se sou branco ou preto... porque já vivi aqui na Europa... Gentes ficavam me olhando assim, mas não me interessa, 'tás a ver, quanto mais aqui que tem milhares de preto... já 'tou acostumado".

Adianta que no meio prisional, até o momento de o conhecerem melhor, muitos têm dificuldade de expressar o seu nome, pelo que muitos pares de reclusão interpelam de: "Ob Black" E eu digo: "Diga". Nesse sentido, Holifu não explicitou nenhum caso particular de conflito aberto. Martynowicz (2016) designou o ensejo das nacionais polacas pretenderem ficar próximas entre $s$ no seio penitenciário irlandês com base, nomeadamente, de uma identidade nacional e numa língua comum de "identidade pragmática grupal" (pp. 342).

Esta investigadora alvitra que se podem formar "prisões dentro de prisões" e que se pode estar a tender para a constituição de mono-boxes culturais em termos de dinâmicas informais no caso de os sistemas prisionais europeus não compreenderem a diversidade sociocultural que têm no meandro do seu parque penitenciário. Quanto ao uso da língua crioula, demonstrou ser a língua que lhe é mais querida, identificável e reconhecida: "Olha, falar em crioulo, me dá mais prazer falar, porque ali não tenho sotaque, nã tenho falbas" (sic) Contudo, sublinhou a limitação do espaço físico em que se pode expressar em crioulo: "(...) mas falo crioulo só na cozinha (compasso de pausa) mas aqui na ala não há ninguém com quem eu fale crioulo"... (sic) Na Guiné-Bissau, quase metade da população nacional fala crioulo, sendo que o português é falado por uma pequena minoria (...) e "a restante população apenas as línguas étnicas” (Machado, 1998), sendo que tal veia identitária é transportada para as formas de como se podem recriar as práticas do dia-a-dia prisional.

A língua-mãe é utilizada enquanto união comungantes nos pontos de encontros em que é passível de haver essa comunhão linguística (a título de exemplo, a mesquita improvisada ou a cozinha). É assinável de que apesar de Holifu ser um país oriundo de língua oficial portuguesa, o seu contato com a língua portuguesa era ínfimo: "Entrei aqui (...) e não sabia falar uma palavra de português, fala em espanhol, fala em deutsch, falava em francês, falava às vezes, em italiano, mas, agora, dou graças a Deus, consigo desenrascar-me..." (sic) Nessa perspetiva, como adiantam Machado e Azevedo (2009) as reconstruções culturais não funcionam em processo auto-circular.

No contexto prisional, Holifu consegue integrar matizes da língua crioula numa vertente tão sagrada (a partilha de uma escolha religiosa) quanto profana (a recreação, a resolução conjunta de problemas contingenciais na estrutura prisional). Essa fluência de crioulo mesclado com outros recortes linguísticos era vivenciada por participantes de diferentes nacionalidades, pelo que a agregação entre pares é feita a partir de outros elementos aglutinadores (como seja a orientação religiosa) além da pertença nacional. Contudo, Holifu demonstrou que na Ala em que coabitava não lhe era viável fazer essa fluência da língua materna, lidando até com processos de estigma racial. Em suma, notam-se linhas de continuidade entre o intramuros e extramuros quer de pertenças-chave que se convocam e plasmam de modo a contornar as vicissitudes prisionais (condicionamento da concretização das práticas religiosas tal como no exterior ou outras privações pessoais / sócio-grupais), quer no sentimento de diferença por marcos identitários como seja a cor de pele.

Ao permanecer-se num dos pátios a céu aberto, podia constatar-se a regularidade diária de um tipo de formato de interação presencial focalizada no lazer: um grupo de guineenses e cabo-verdianos que estavam na mesma mesa, sempre que podiam, a jogar às cartas. Entre os presentes, só se falava em crioulo, um crioulo que não era genuinamente de Cabo-Verde, nem da Guiné-Bissau.

O participante da amostra de nacionalidade cabo-verdiana, de ora em diante de nome fictício Djamil, no desenrolar da entrevista em profundidade, verbalizou que no princípio de se encontrar recluído lhe fazia confusão fundir os crioulos de ambos os países, os quais têm nuances próprias, mas depois passou a parecer-lhe "claro como água" (sic). O fruir linguístico do crioulo de ambos os países fomentava um cariz de sociabilidade com apontamentos realçáveis de criatividade e de flexibilidade, sendo que essa transmutação linguística cativava a aproximação entre reclusos com afinidades socioculturais comuns e substanciava práticas de entretenimento.

Desse modo, notaram-se linhas de continuidade entre o intramuros e o extramuros quer de um passado mais recente e de um passado histórico mais secular em que a historicidade colonial de ambos os países provocaram laços históricos da mais diferente natureza (desde a comercial à político-partidária) (Albuquerque e Madeira Santos, 2001; Machado, 1994). Quer na GuinéBissau, quer em Cabo-Verde, o crioulo é muito prevalecente nas oralidades dos ritmos quotidianos. Durante a entrevista, Djamil explicou como é que os falantes de crioulo de Cabo-Verde e da Guiné dão sentidos diferentes à mesma construção frásica mas nem por isso deixam de apropriar / usar ambas as línguas maternas: "Sim, porque, às vezes, usamos as expressões deles, às vezes, 
utilizamos as nossas”... (sic) Demonstrou muito sentido humor a fazer as discrepâncias das variações linguísticas. Essa combinação linguística informalizada dentro dos muros da prisão demonstrava ser uma fórmula extraordinária já incorporada nas práticas quotidianas do dia-a-dia prisional tida como fruto de laços socioculturais e influências dos seus países de proveniência e percursos comuns de reclusão.

A conversa no pátio fez denotar laivos de hermetismo sociocultural e até de tensão racial, revelando sentimentos de exclusão por parte de outras pertenças raciais / nacionais. Djamil rematou com uma explanação sumária: "É ka mi ki começa" (tradução livre do crioulo de Cabo-Verde: "Não fui que comecei”) (sic, tal como nota de campo). Tal expressão justificativa sugeria apontar dinâmicas de animosidade entre pares de diferentes nacionalidades acentuadas por cores de pele dissemelhantes. No curso da entrevista em profundidade, Djamil fez alusões constantes a experiências de racismo quer feitas por pares de reclusão que não tinham a sua cor de pele, quer por parte de vários elementos do staff prisional. A um dado momento adiantou: "(...) São um bando de racistas que aí andam... (...) Todos... Mas, a diferença entre guardas e reclusos é só a farda... É a mesma organização... É melhor eu parar, senão... Já falei até demais" (sic).

Durante a aplicação da entrevista, Djamil optou por falar na sua língua-mãe que era o língua cabo-verdiana, o crioulo, mais precisamente da Ilha de Santiago. Demonstrava umaenorme satisfação face ao fato de poder fazer uma entrevista com alguém que era filha de um oriundo cabo-verdiano, fazendo-se explicitar por moldes físicos, com as pontas dos dedos. "Para mim, basta ter uma pontinha de cabo-verdiano" (sic). Tal pode fazer indicar que aquando em reclusão, há uma ânsia de reconhecimento e de co-identificação. A língua cabo-verdiana revelou-se ser utilizada por Djamil com o intuito de ampliar as possibilidades de lazer em contexto de reclusão, tendo feito a importação e transmudação da sua língua materna para o seio prisional. Djamil já residia em Portugal antes da situação de reclusão mas é em Cabo-Verde que tem a sua rede familiar de suporte, como seja a mãe e a filha, lamentando até a falta de pureza da expressão do seu crioulo: "E ainda por cima os seus crioulos ainda são mais diferentes que o meu... O meu, já alterou um pouco... Os seus, está o mesmo crioulo.” (sic) No decorrer desta técnica, fez alusões críticas e sagazes aos ritmos institucionais, na sua própria língua nacional. Num dardo verbal repentino, satírico e metafórico interpelou: "Odja Michael Jackson pa la" (tradução livre a partir do crioulo de Cabo-Verde: "Olha ali o Michael Jackson"), ou seja, de que um guarda prisional observava a entrevista de forma excessiva, passando de pouco em pouco tempo, por permeio de um vidro.

$\mathrm{O}$ discurso de Djamil ainda apontou para um outro aspeto. $\mathrm{Na}$ sua leitura crítica, há uma gradação de racismo no âmago prisional. "Eles são fodidos... mas, eles não acham que eu sou preto... eles estão a separar três coisas aqui...” (sic) Ou seja, é como se como o tratamento oficial ou a interpelação informal fosse feita em função do que se supunha a partir da cor de pele. Este testemunho é coincidente com as experiências de vitimização de racismo institucional detetadas por Gomes (2017) relativamente a elementos do Corpo da Guarda Prisional e pelas posturas profissionais auscultadas no levantamento empírico de Gomes, Machado e Silva (2012). Porém, estas experiências de percepção de racismo não foram verificadas nos resultados empíricos de RuízGarcia e Castilla-Algarra (2014), em que adiantam que as reclusas estrangeiras não demonstraram experiências de racismo dentro do meio prisional quer por parte de outras reclusas, quer por parte dos intervenientes institucionais. No entanto, estas mesmas autoras referiram que se pode encontrar uma tendência para a ghetização entre as diferentes nacionalidades. Já Cunha (2002) adiantou que o binómio racial não se traduzia na sua pesquisa, sobressaindo mais uma generalização entre cabo-verdianas e ciganas, sendo que a primeira atribuição agregava mulheres de diferentes nacionalidades. Esta autora adiantou ainda que a consonância da situação de reclusão e de pertença de classe levava a um sentido de comunidade mais aglutinador - mesmo com todas as conflitualidades intra-prisionais - do que havia encontrado na sua incursão in situ dez anos atrás. Não obstante, no curso da pesquisa que ora se desfia fizeram salientar-se lógicas quer de aproximação quer de separatismo identitário marcadas por outras sub-pertenças à semelhança do relatado por Matos (2016). É de notar que, embora Djamil faça transparecer uma preferência de co-identificação com os guineenses em reclusão, a construção do seu "Nós" ao longo da entrevista era referente aos outros cabo-verdianos, como se reforçasse um sentido de coesão grupal nacional: "A nôs é descontra. [expressão idiomática para fazer corresponder de que os cabo-verdianos são descontraídos] ... Nós safamos-nos sempre." (sic) Quando Djamil se referia aos guineenses designava-os como: "Eles" como se, mesmo que com todos os traços de parentesco sociocultural, fizessem mais parte da sua alteridade do que da sua auto-pertença identitária: "Há uma diferença entre falar crioulo com o ser crioulo. São duas coisas diferentes". (sic).

Nesse sentido, mesmo que o pátio possa ser aproveitado por forma a diluir o impacto da pena efetiva com referenciais que podem ser fundidos como seja o entrelaçamento das suas línguas maternas: "é isso, jogar às cartas, apanhar Sol, dar voltas, discutir futebol, falar de namoradas, falar de família, telefonemas que fizeram à família... o pátio é basicamente isso"...(sic) não quer dizer que haja uma simbiose identitária mesmo entre aqueles que privam histórias coletivas mais comuns. Djamil partilhou ir para a cela, ao fim de tarde, com outros cabo-verdianos mais velhos para contar o que se passava com eles lá dentro, tendo referido serem todos badius... (oriundos da Ilha de Santiago). 
A aparente inflexibilidade face ao "Outro" conjugava-se com uma abertura para a combinação de aspetos linguísticos de pares de reclusão de outros países. Ao encontrar Djamil na unidade laboral a que estava adstrito com um par de reclusão de nacionalidade italiana, o primeiro falava frases quer em língua crioula quer em língua italiana, em virtude de considerar ser assim mais fácil comunicarem e se entenderem, sendo que o dizia entre risadas e trejeitos humorísticos. Mais uma vez, pode afirmar-se que o uso da língua-mãe é utilizado da forma mais presente e regular possível, mesmo que moldada e circunstanciada às condicionantes mais imediatas e aos intervenientes presentes.

\section{Súmula conclusiva}

Em ambos os testemunhos e episódios acima relatados, podemos encontrar pontos de analogia como seja o uso do crioulo nas suas práticas informais preferenciais. O recurso à língua-mãe faz convocar vivências pregressas anteriores à reclusão bem como se torna uma expressão de reconhecimento e de demarcação simbólica entre pares. As práticas de sociabilidade ora integradas no tempo de labor ora no tempo livre, demonstram-se enquanto respostas de "sobrevivência institucional" no sentido que se revelam enquanto modos de suplantar óbices e ausências inerentes à determinação da medida judicial aplicada.

A importação da língua-mãe, em modalidades metamorfoseadas, possibilitam ainda a construção de redes de suporte efetivas e afetivas tão parecidas quanto possível ao meio livre. Além do mais, a restituição do crioulo nas suas práticas de lazer dentro de muros torna-se um veículo de coesão grupal e de sentido de pertença identitária a qual não pode ser entendida de forma imutável (Resende, 2008 a). Tal fluência ajuda também a (re)definir e versar o ambiente social em que se encontram com sentidos próprios e autenticados entre si.

Para além disso, ambos os relatos apontaram formas gradativas de racismo o que mais pode mover o ímpeto para estabelecer vínculos preferenciais com quem percepcionam não lhes fazer essas marcações segundo discriminação negativa. O crioulo, enquanto pertença-chave de identidade nacional, era transmudado e partilhado com quem revelava lógicas de aceitação e vinculação social, com símbolos nacionais comuns germinados por laços históricos e / ou religiosos. A língua-mãe faz parte da bagagem cultural dos participantes a qual é transportada para o meio prisional segundo fins próprios. No essencial, o crioulo pode ser visto enquanto resposta de resistência na vertente do lazer em contraponto a ritmos muito estandardizados tais como os passíveis de ocorrer em meio prisional. Todavia, constatou-se uma flexibilidade quer na recriação do uso da própria língua, quer na aprendizagem de outros saberes linguísticos precisamente por forma a evitarem o isolamento social.

Assimetricamente, Trombik (2007) constatou que reclusos alemães num estabelecimento prisional francês, preferiam remeter-se ao autoisolamento nas celas, em virtude que já bastava terem que cumprir a pena de prisão em França, pelo que não queriam sentir-se forçados a ter que aprender a língua do país que os condenou a uma medida privativa de liberdade. As linhas de (de)marcação identitária entre pares de reclusão caboverdianos e de Leste através de processos de estereotipificação, feita sobretudo com teor negativo, foi esmiuçada por Gomes, O. (2012), ao ponto de ter intitulado a sua monografia de "Prisão com fronteiras".

Aprofundar as as linhas delimitantes entre a conflitualidade manifesta e / ou latente, o ensejo de afirmação cultural entre reclusos de diferentes nacionalidades e as possibilidades de amplitude da multiculturalidade dentro de muros (Shammas, 2015) continua a revelar-se digno de estudo.

\section{Bibliografia}

ALBUQUERQUE, Luis de e MADEIRA SANTOS, Maria Emília (2001); "História Geral de Cabo-Verde", Volume I, $2^{a}$ Edição, Instituto de Investigação Científica Tropical - Portugal - Lisboa / Instituto Nacional de Investigação Cultural - Cabo-Verde - Praia.

BANDYOPADHYAY, Mahuya (2010); "Everyday life in a Prison - Confinement, Survellaince, Resistance", Orient BlackSwan.

BLUMER, Herbert (1992(1969)); “Symbolic Interactionism”, University of California Press.

BOE, Carolina Sanchez (2016); "From banlieue youth to undocumented migrant: Illegalized foreign-nationals in penal institutions and public space”, Criminology \& Criminal Justice, Vol 16 (3); pp. 319-336.

BOSWORTH, Mary, HASSELBERG, Inês e TURNBULL, Sarah (2016); "Punishment, citizenship and identity: An introduction”, Criminology \& Criminal Justice, pp. 1-10.

BOUVIER, Pierre (2000); “La Socio-Anthropologie”, Éditions Armand Colin.

BRION, Fabienne (2014); "PRISONS BELGES: LES ÉTR ANGERS EN PREMIÈRE LIGNE", Entrevista a Media 4 Perspetives, conforme consultado a 24 de Agosto de 2016

CANTON, Rob e HAMMOND, Nick (2012); "Foreigners to Justice? Irregular migrants and foreign national offenders in England and Wales", European Journal of Probation, pp. 4-20

COYLE, Andrew (2005); « Understanding prisons: Key issues for policy and practice», Open University Press

CUNHA, Manuela Ivone (2014) ; "Etnografias da prisão : novas direções ", 13, Revista Configurações, Tema : Trabalho e Justiça

CUNHA, Manuela Ivone (2005): «El tiempo que no cesa - La erosión de la frontera carcelaria”, Renglones, 58-59, Noviembre de 2004-Abril de 2005

CUNHA, Manuela Ivone (2002); “Entre o bairro e a prisão - Tráfico e Trajetos”, Fim de Século

DGRSP [intranet] (2017); "População prisional por tipo de estabelecimento, segundo a situação penal em 1 e 15 de março de 2017”, tal como disposto em sítio eletrónico oficial da DGRSP: http://www.dgsp.mi.pt/ 
DGRSP [intranet] (2016); "Lotação e reclusos existentes em 31 de dezembro"

DGRSP [intranet] (2017); "População prisional, por tipo de estabelecimento, segundo a situação penal em 1 e 15 de setembro de 2017 ".

DGRSP [intranet] (2017); "População prisional, por tipo de estabelecimento, segundo a situação penal em 15 de junho e 1 de julho de 2017".

DGRSP [intranet] (2017); "População prisional, por tipo de estabelecimento, segundo a situação penal em 1 e 15 de fevereiro de 2017".

DGRSP [intranet] (2016); "Reclusos existentes a 31 de Dezembro, segundo a situação penal, por sexo e por nacionalidade".

DGRSP [intranet] (2016); "Reclusos existentes a 31 de Dezembro, segundo o escalão etário, por sexo e por nacionalidade".

DGRSP / DGSP (2015); "Reclusos existentes a 31 de Dezembro, segundo a situação penal, por sexo e nacionalidade", tal como disposto em sítio eletrónico oficial da DGRSP: http://www.dgsp.mj.pt/.

DGRSP / DGRSP (2015); "Reclusos existentes a 31 de Dezembro, segundo a situação penal, por sexo e nacionalidade", tal como disposto em sítio eletrónico oficial da DGRSP: http://www.dgsp.mj.pt/.

DGSP (2011); "Nacionalidade dos reclusos por sexo e idade" (2a Trimestre).

DGSP (2010); "Reclusos existentes em 24-11-2010 por Situação Penal, Sexo, Nacionalidade e Estabelecimento Prisional".

DGSP (2010 a); "Distribuiç̃ao dos reclusos por nacionalidades e por Estabelecimento a 24-11-2010"

EDGAR, Kimmet, O’DONNEL, Ian e MARTIN, Carol (2012); “Prison violence, - The dynamics of conflict, fear and power", Routdledge.

ELIAS, Norbert e DUNNING, Eric (1999 [1985]); “A busca da excitação - desporto e lazer no processo civilizacional", DIFEL.

ESTEVES, Alina e MALHEIROS, Jorge (1999); «Os cidadãos estrangeiros nas prisões portuguesas: "Sobrerepresentação ou ilusão? », Inforgeo, Lisboa, Edições Colibri, pp. 77-102.

FONSECA, Graça (2010); "Percursos estrangeiros no Sistema de Justiça penal", Observatório de Imigração, ACIDI.

GARLAND, David (2001); "The culture of control - Crime and social order in contemporary society" Oxford Press.

GOFFMAN, Erving (1988); "Lordre de l'interaction” in «Les moments et leurs hommes» - «Textes Recueillis et Présentés par Yves Winkin», Seul/ Minuit, Local de Edição (?).

GOMES, Silvia (2017); "Access to Law and Justice perceived by Foreign and Roma Prisoners", Race and Justice, Article first published online: March 30, 2017

GOMES, Sívia (2015); "Caminhos para a prisão - Uma análise do fenómeno da criminalidade associada a grupos estrangeiros e étnicos em Portugal", Húmus

GOMES, Sílvia, MACHADO, Helena e SILVA, Manuel Carlos (2012); "Grupos étnicos e estrangeiros em contexto prisional: representações de guardas prisionais e elementos da direção", VII Congresso de Sociologia, Porto, Comunicação.

GOMES, Orlando (2012); "Prisão com fronteiras: Relações interétnicas em meio prisional. Estudo de caso no Estabelecimento Prisional da Carregueira", Dissertação de Mestrado em "Migrações, Interetnicidade e Transnacionalismo", UNL.

GUIA, Maria João (2008); “Imigração e Criminalidade - Caleidoscópio de Imigrantes Reclusos", Ed. Almedina.

KAUFMAN, Emma e BOSWORTH, Mary (2013); "The prison and national identity: citizenship, punishment and the sovereign State” em "Why Prison?”, Scott, d., Cambridge, Cambridge University Press.

KALMTHOUT, F.B.A.M Van; DER MEULEN, Hofstee-van e DUNKEL, F. (Eds.) (2007); "Foreigners in European Prisons - Volumes 1 et 2", Wolf Legal Publishers.
HASSELBERG Inês (2014): "Coerced to leave: Punishment and the surveillance of foreign-national offenders in the UK", Surveillance \& Society, 12 (4): pp. 471-484.

HOSTETTLER, Ueli e ACHERMANN, Christin (2008); «Cidadãos estrangeiros em duas prisões na Suíça: Vida prisional, reabilitação e destino pós-reclusão" in "Aquém e além da prisão - Cruzamentos e Perspectivas", Manuela Ivone Cunha (Org.), Editora 90.

JAVEAU, Claude (2003); "Sociologie de da vie quotidienne", Presses Universitaires de France.

MACHADO, Fernando Luis e AZEVEDO, Joana (2009); "A investigação sobre imigração e etnicidade em Portugal: tendências, vazios e propostas", Revista Migrações, Abril 2009, nº 4, Lisboa: ACIDI, pp. 7-31.

MACHADO, Fernando Luis (1998); “Da Guiné-Bissau a Portugal: Luso-guineenses e imigrantes", Sociologia - Problemas e Práticas, nº 26, pp. 9-56.

MACHADO, Fernando Luis (1994); “Luso-africanos em Portugal: nas margens da etnicidade", Sociologia Problemas e Práticas, № 16, pp. 111-134.

MARTYNOWICZ, Agnieszka (2016); "Not so multicultural prison: Polish prisoners in a transitional prison system", Criminology \& Criminal Justice, vol. 16 (3), pp. 337-349.

MATOS, RAQUEL (2016); "Trajectories and identities of foreign national women: Rethinking prison through the lens of gender and citizenship", Criminology \& Criminal Justice, Vol. 16 (3), pp. 350-365.

MATOS, Raquel, BARBOSA, Mariana, SALGUEIRA, Gabriela e MACHADO, Carla (2013); "Cidadãos estrangeiros em Portugal: Migrações, Crime e Reclusão", Psicologia, Vol. XXVII (I), Edições Colibri, pp. 33-45.

MORAES ROCHA, João Luis (2001); "Reclusos Estrangeiros - Um Estudo Exploratório", Ed. Almedina.

MULGREW, Roisin (2016); "Foreign Prisoners in Europe: An Analysis of the 2012 Council of Europe Recommendation and its Implications for International Penal Policy", Review of International Law \& Politics, Vol. 12, no 1, pp. 161-200.

MULGREW, Roisin (2016 a); "Foreign Prisoners: Findings of a study in Foreign Nationals only prisons in Norway and the Netherlands", CEP - Confederation of European Probation, tal como consultado a 10 de Novembro de 2016 através do link: http://cep-probation.org/foreign-prisoners-findings-of-a-studyin-foreign-national-only-prisons-in-norway-and-the-netherlands/.

OLIVEIRA, Catarina Reis e GOMES, Natália (2014): "Monitorizar a integraç̃o de Imigrantes em Portugal", Imigração em Números - Relatório Estatístico Decenal, Observatório das Migraç̃es, Dezembro de 2014.

PAIS, José, Machado, BENDIT, René e SÉRGIO FERREIRA, Victor (Orgs.) (2011); “Jovens e Rumos", Instituto de Ciências Sociais, Lisboa.

PAIS, José Machado (2007); “Sociologia da Vida Quotidiana - Teorias, Métodos e Estudos de Caso", Ed. ICS (Imprensa de Ciências Sociais).

PAIS, José Machado (1994); “A vida como aventura: uma nova ética do lazer?", New routes for leisure", Actas do Congresso Mundial do Lazer / World Leisure Congress, Lisboa, 3-5 de Junho de 1992.

PAIS, José Machado (1998); "As 'cronotopias' das práticas culturais do quotidiano", Versão electrónica do artigo da publicação periódica do Observatório das Actividades Culturais, OBS, nº 4, pp. 7-9.

PAPAVERO, Giorgia (2015); "I detenuti stranieri in Italia", Fondazione ISMU - INIAZIATIVE E STUDI SULLA MULTIETNICITÀ, Fact sheet ISMU - Luglio 2015.

PAULINO, Mauro, CONDUTO, Ana Luísa e PIRES, Dulce (2014); “A reclusão de cidadãos brasileiros em Portugal: Impacto na sociedade, cumprimento da pena e reinserção", Perspectivas em Psicologia, Vol. $18, \mathrm{n}^{\circ} 1$, Jan/ Jun, pp. 175-193.

RUIZ-GARCIA, Marta \& CASTILLO-ALGARRA, Joaquina (2014); "Experiences of foreign women in Spanish prisons", Journal of Offender Rehabilitation, 53:8, 587-599.

RESENDE Cláudia (2016): “Do grupo esquecido' ao grupo que não se faz esquecer" no painel "Estudos desenvolvidos em estabelecimento prisional" no I Encontro "Espaços de Reclusão - Desafios na Profissão e na Investigaç̃ão", ISMAI, Maia, 27 de Outubro de 2016. 
RESENDE, Cláudia (2014); "Da expressão estatística às vivências quotidianas - Cabo-verdianos em reclusão”, Associação Cabo-Verdiana de Lisboa, 6 de Novembro. RESENDE, Cláudia (2008); "Normalização: Um conceito-chave na filigrana das dinâmicas prisionais" in "Aquém e além da prisão - Cruzamentos e Perspectivas”, Manuela Ivone Cunha (Org.), Editora 90 .

RESENDE, Cláudia (2008 A); "Raça, Racismo e Etnicidade: Conceitos pouco visíveis num contexto pouco visível”, V Congresso Português de Sociologia, Universidade Nova de Lisboa - Faculdade de Ciências Sociais e Humanas, 25 a 28 de Junho, Comunicação.

SEABRA, Hugo Martinez e SANTOS, Tiago (2006); "Reclusos Estrangeiros em Portugal - Esteios de uma Problematização", OI - Observatório da Imigração, Ed. Alto Comissariado para a Imigração e Minorias Étnicas, Coleção Teses.

SEMEDO MOREIRA, J. J. (2014); “Aritmética breve em torno dos reclusos estrangeiros” em "Género, nacionalidade e reclusão - Olhares cruzados sobre migrações e reclusão feminina em Portugal”, (Coord) Raquel Matos, Universidade Católica Editora, Porto.

SHAMMAS, Victor (2015); "Denying the danger of difference: Notes on the pacification of inmate social relations in an era of ethnoracial diversity", Prison Service Journal, Issue 219, pp. 3-pp.8.

SINGH BHUI, H. (2004): "Developing Effective Practice and Policy with Foreign National Prisoners, Prison Reform Trust.

SLADE, Lucy (2015); "Foreign National Prisoners; best practice in prison and resettlement”, Prison Reform Trust.

SPACE I - PRISON POPULATIONS [2017 (2015)]; “ANNUAL PENAL STATISTICS”, AEBI, Marcelo, MÉLANIE, Tiago, BURKHARDT, Christine, Final Report .

TROMBIK, Emily (2007) ; "L'incarcération des détenus allemands en France : perspectives et limites des projets de réinsertion», Champ Pénal / Penal Field, Nouvelle Revue Internationale de Criminologie, Numéro Vol. IV, pp. 1-14.

TURNBULL, Sarah e HASSELBERG, Inês (2016) ; « From prison to detention : the carceral trajectories of foreign-national prisoners in the United Kingdom », Punishment \& Society, pp. 1-20.

UGELVIK, Thomas (2014); "The incarceration of foreigners in European Prisons" in "Routledge Handbook on Crime and International Migration", Sharon Pickering e Julie Ham (eds.), London \& New York, Routledge.

UGELVIK, Thomas (2014 a); "Paternal pains of imprisonment: incarcerated fathers, ethnic minority masculinity and resistance narratives", 16, pp. 152-168.

WACQUANT, Loic (2004); « Punir les pauvres - Le nouveau gouvernement de l'insecurité sociale », Agone.

WACQUANT, Loic (1999); “Suitable Enemies': Foreigners and Immigrants in the prisons of Europe”, Punishment \& Society, Sage Publications, Vol. 1 (2), pp. 215-222.

WELZER-LANG, Daniel, MATHIEU, Lilian e FAURE, Michael (1996[2éme édition]); «Sexualités et violences en prison - Ces abus qu’on dit sexuels...», Observatoire International des Prisons, Aléas Éditeur.

YOUNG REVIEW TASK GROUP (2014); "Improving outcomes for young black and Muslim males in the Criminal Justice system", January. 